STRUCTURAL SCIENCE CRYSTAL ENGINEERING MATERIALS

ISSN 2052-5206

Received 16 February 2021

Accepted 14 April 2021

Edited by A. J. Blake, University of Nottingham, United Kingdom

Keywords: high pressure; crystallization; polymorphs; phase transitions; hydrate.

CCDC references: 2061304-2061320

Supporting information: this article has supporting information at journals.iucr.org/b

\section{High-pressure and environment effects in seleno- urea and its labile crystal field around molecules}

\author{
Kinga Roszak and Andrzej Katrusiak*
}

Deparment of Material Chemistry, Adam Mickiewicz University, Uniwersytetu Poznańskiego 8, Poznań, 61-614, Poland. *Correspondence e-mail: katran@amu.edu.pl

Ambient-pressure trigonal phase $\alpha$ of selenourea $\mathrm{SeC}\left(\mathrm{NH}_{2}\right)_{2}$ is noncentrosymmetric, with high $Z^{\prime}=9$. Under high pressure it undergoes several intriguing transformations, depending on the pressure-transmitting medium and the compression or recrystallization process. In glycerine or oil, $\alpha-\operatorname{SeC}\left(\mathrm{NH}_{2}\right)_{2}$ transforms into phase $\beta$ at $0.21 \mathrm{GPa}$; however in water, phase $\alpha$ initially increases its volume and can be compressed to $0.30 \mathrm{GPa}$ due to the formation of $\alpha$-SeC $\left(\mathrm{NH}_{2}\right)_{2} \cdot x \mathrm{H}_{2} \mathrm{O}$. The single crystals of $\alpha-\mathrm{SeC}\left(\mathrm{NH}_{2}\right)_{2}$ and of its partial hydrate $\alpha$-SeC( $\left(\mathrm{NH}_{2}\right)_{2} \cdot x \mathrm{H}_{2} \mathrm{O}$ are shattered by pressure-induced transitions. Single crystals of phase $\beta$-SeC $\left(\mathrm{NH}_{2}\right)_{2}$ were in situ grown in a diamond-anvil cell and studied by X-ray diffraction. The monoclinic phase $\beta$ is centrosymmetric, with $Z^{\prime}=2$. It is stable to $3.20 \mathrm{GPa}$ at least, but it cannot be recovered at ambient conditions due to strongly strained NH . . Se hydrogen bonds. No hydrogenbonding motifs present in the urea structures have been found in selenourea phases $\alpha$ and $\beta$.

\section{Introduction}

By crystallographic standards, selenourea $\mathrm{SeC}\left(\mathrm{NH}_{2}\right)_{2}$ is intriguing, because it forms crystals of enantiomorphic spacegroup symmetry, either $P 3_{1}$ or $P 3_{2}$, with nine independent molecules in the structure. Such structures with $Z^{\prime}=9$ are very rare and only 17 of them have been reported so far, which constitutes about $1.2 \times 10^{-5}$ of crystals currently deposited in the Cambridge Structural Database (Groom et al., 2016). Selenourea is by far and away the smallest and the simplest compound in this group of 17 crystals, in terms of the number of atoms (eight) and the rigid structure of the molecule. Thus the high $Z^{\prime}$ in selenourea cannot be due to conformational differences between molecules, but it is solely due to their different packing motifs. The aggregation of molecules can be characterized by the configuration and conformation of the NH...Se hydrogen bonds (Fig. 1).

We have undertaken this study of $\mathrm{SeC}\left(\mathrm{NH}_{2}\right)_{2}$ to check if high pressure would increase or decrease its $Z^{\prime}$ number and what would be the mechanism of such a change. It can be assumed that high pressure induces changes in properties and structure analogous to those at low temperature; hence the rule of inverse effects of pressure and temperature (Hazen \& Finger, 1982). In the literature there are several compounds confirming this type of change in the $Z^{\prime}$ number positively coupled to pressure. For example, in ethynylbenzene (Dziubek et al., 2007) the $Z^{\prime}$ number increases from 2.5 to 3; in pyrazine (Patyk et al., 2015) from 0.25 to 0.5; in chlorpropamide (Seryotkin et al., 2013) from 1 to 2. Likewise, in thiourea (Tomkowiak \& Katrusiak, 2018) $Z^{\prime}$ in the ambient-pressure phase $\mathrm{V}$ is equal to 1 and in high-pressure phase VI the $Z^{\prime}$ 
(a)

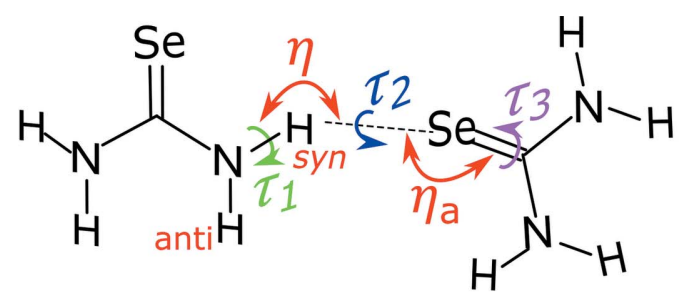

(b)

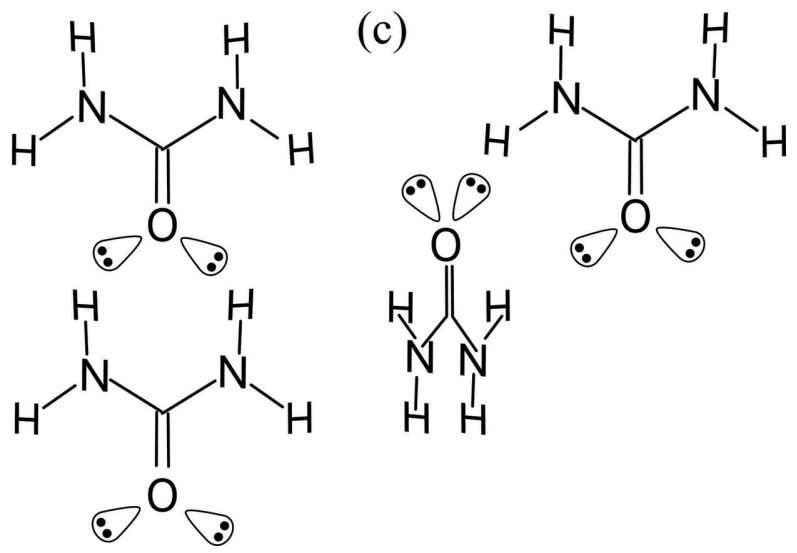

Figure 1

Configurations and conformations of NH...Se hydrogen bonds between selenourea molecules $(a)$ as well as two main hydrogen-bonding modes involving (b) anti and (c) syn hydrogen bonds in urea. Torsion angles $\tau_{1}$, $\tau_{2}$ and $\tau_{3}$ and bond-H-bond angles $\eta$ and $\eta_{\mathrm{a}}$ describing the hydrogenbond geometry ( $c f$. Fig. S1-S3).

number increases to 3; the urea (Olejniczak et al., 2009; Roszak \& Katrusiak, 2017) crystal transforms from the ambient-pressure phase I $\left(Z^{\prime}=0.25\right)$ to phase III $\left(Z^{\prime}=1\right)$ at $0.48 \mathrm{GPa}$.

On the other hand, it can be argued that high pressure increases the potential energy $E_{\mathrm{p}}$ for intermolecular interactions, which differ for independent molecules. Hence high pressure increases intermolecular interactions and the potential energy $E_{\mathrm{p}}$ of the crystal can be reduced by eliminating the independent molecules with the highest $E_{\mathrm{p}}$ (Le Chatelier's principle), which affects the crystal symmetry and reduces $Z^{\prime}$. Numerous examples of such a behaviour were reported: 4,4'-bipyridinium perchlorate undergoes a phase transition from space group $P \overline{1}\left(Z^{\prime}=2\right)$ at $0.1 \mathrm{MPa}$ to space group $C m c 2_{1}$ at $0.30 \mathrm{GPa}, Z^{\prime}=0.5$ (Anioła \& Katrusiak, 2017); $\gamma$-CD-MOF-1 space group $R 32\left(Z^{\prime}=1\right)$ at $0.1 \mathrm{MPa}$ to space group $I 432$ at $0.16 \mathrm{GPa}, Z^{\prime}=0.25$ (Patyk-Kaźmierczak et al., 2017) and others (Olejniczak \& Katrusiak, 2008; Marciniak et al., 2016; Andrzejewski \& Katrusiak, 2017).

The selenourea crystals are intriguing also in other respects. The three sister compounds of the urea family: urea $\mathrm{OC}\left(\mathrm{NH}_{2}\right)_{2}$, thiourea $\mathrm{SC}\left(\mathrm{NH}_{2}\right)_{2}$ and $\mathrm{SeC}\left(\mathrm{NH}_{2}\right)_{2}$ differ significantly in their physical and chemical properties. For example, the ambient-pressure phase I of urea does not transform as a function of temperature, whereas thiourea displays five temperature-dependent phases. Both urea and thiourea undergo several phase transitions under pressure. No phase transitions were reported for selenourea so far. Compared to urea and thiourea, the ambient-pressure structure of $\mathrm{SeC}\left(\mathrm{NH}_{2}\right)_{2}$ is unique and presently we have investigated the reasons for its large $Z^{\prime}$ number. Moreover, urea is known to co-crystallize easily (Girard et al., 1997, 1998; Hollingsworth et al., 1999, 2002a, 2002b, 2005; Toudic et al., 2008), but no solvates of urea are known (Roszak \& Katrusiak, 2017). Thiourea behaves similarly (Taouss et al., 2013), but two thiourea hydrates were obtained under pressure (Tomkowiak et al., 2013). Thus we also intended to investigate the possibility of forming hydrates of $\mathrm{SeC}\left(\mathrm{NH}_{2}\right)_{2}$ under pressure. Finally, by including the pressure variable into the thermodynamic conditions, we aimed at finding common aggregation motifs for these three urea analogues.

\section{Experimental}

We performed high-pressure experiments on $\mathrm{SeC}\left(\mathrm{NH}_{2}\right)_{2}$ either by gradually compressing a single crystal or by highpressure recrystallizations, and growing single crystals in isothermal and isochoric conditions from methanol and aqueous solutions. High-pressure experiments were performed in a Merrill-Bassett diamond anvil cell (DAC, Merrill \& Bassett, 1974), modified by mounting the anvils directly on steel backing plates with conical windows (Katrusiak, 2008).

The structures of high-pressure phases were determined by single-crystal X-ray diffraction. The compression of the $\mathrm{SeC}\left(\mathrm{NH}_{2}\right)_{2}$ crystal was determined for the sample grown at ambient conditions and then mounted in the DAC. The gasket was made of $0.20 \mathrm{~mm}$-thick Inconel foil and the initial diameter of the spark-eroded hole was $0.45 \mathrm{~mm}$. Glycerine was used as the hydrostatic medium. Pressure in the DAC chamber was calibrated by the ruby fluorescence method (Piermarini et al., 1975; Mao et al., 1986) with a Photon Control Inc. spectrometer, affording an accuracy of $0.02 \mathrm{GPa}$. The calibration was performed before and after each diffraction data collection, which confirmed no significant changes in the pressure, exceeding 1.96 nominal accuracy; the reported pressure values are those of the second calibration.

The compression of $\mathrm{SeC}\left(\mathrm{NH}_{2}\right)_{2}$ phase $\alpha$ in glycerine was possible to $0.21 \mathrm{GPa}$, when the sample crystal started to crack. In the transmitting light (Figs. $2 a$ and $2 b$ ) it looked like darkening of the otherwise transparent crystal, but the top illumination of the sample (Fig. $2 c$ ) showed that this darkening
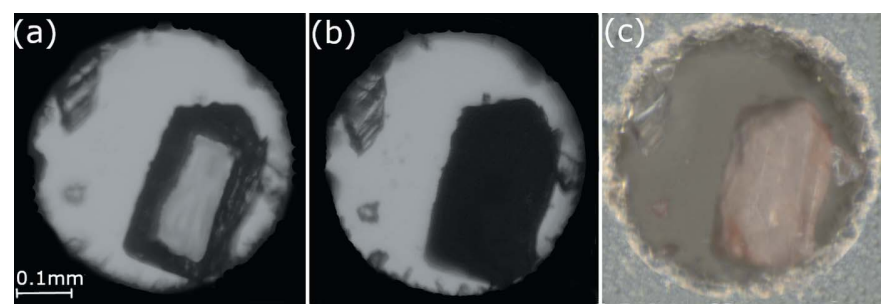

Figure 2

Selenourea single crystal at (a) $0.1 \mathrm{MPa},(b)$ this sample at $0.23 \mathrm{GPa}$ after its transformation, seen in transmitting light, and $(c)$ the same sample illuminated from above $0.42 \mathrm{GPa} / 296 \mathrm{~K}$. Several ruby chips lie close to the edge of the chamber. 

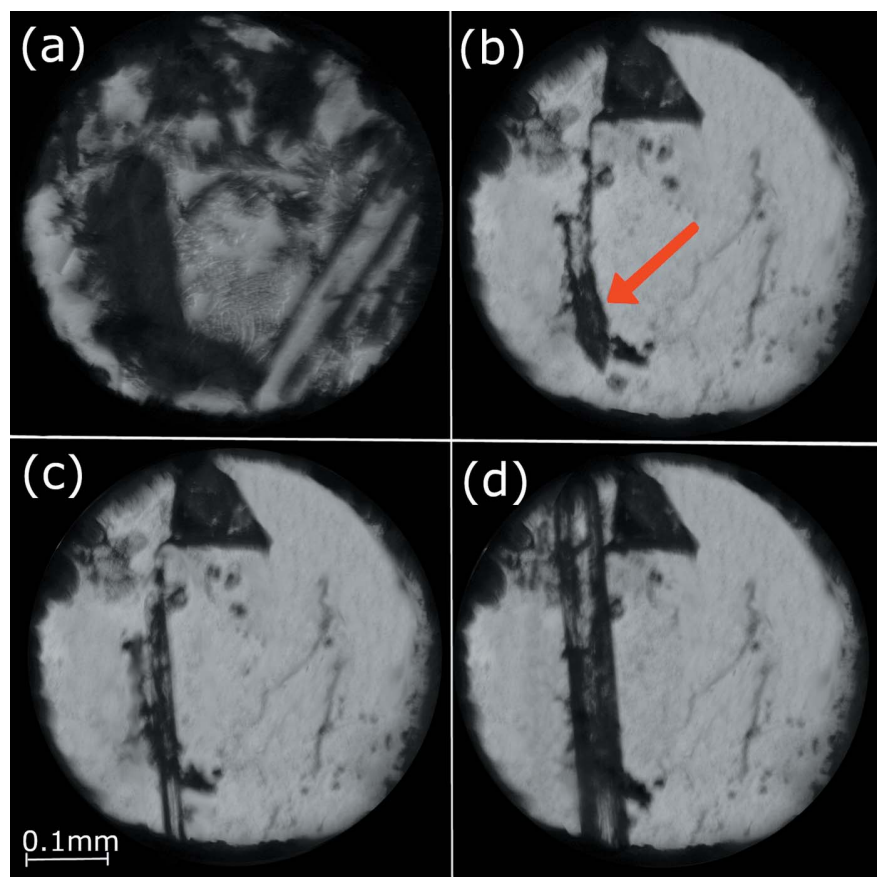

Figure 3

Stages of $\alpha$-SeC( $\left(\mathrm{NH}_{2}\right)_{2}$ single-crystal growth from the aqueous solution under isochoric conditions in the DAC chamber: $(a)$ spontaneous powder precipitation at $0.18 \mathrm{GPa}$ (it required $333 \mathrm{~K}$ to dissolve), $(b)$ one seed (indicated by the red arrow) at $323 \mathrm{~K},(c) 315 \mathrm{~K}$ and $(d) 0.18 \mathrm{GPa} / 296 \mathrm{~K}$. The ruby chip for pressure calibration is located close to the gasket top edge.
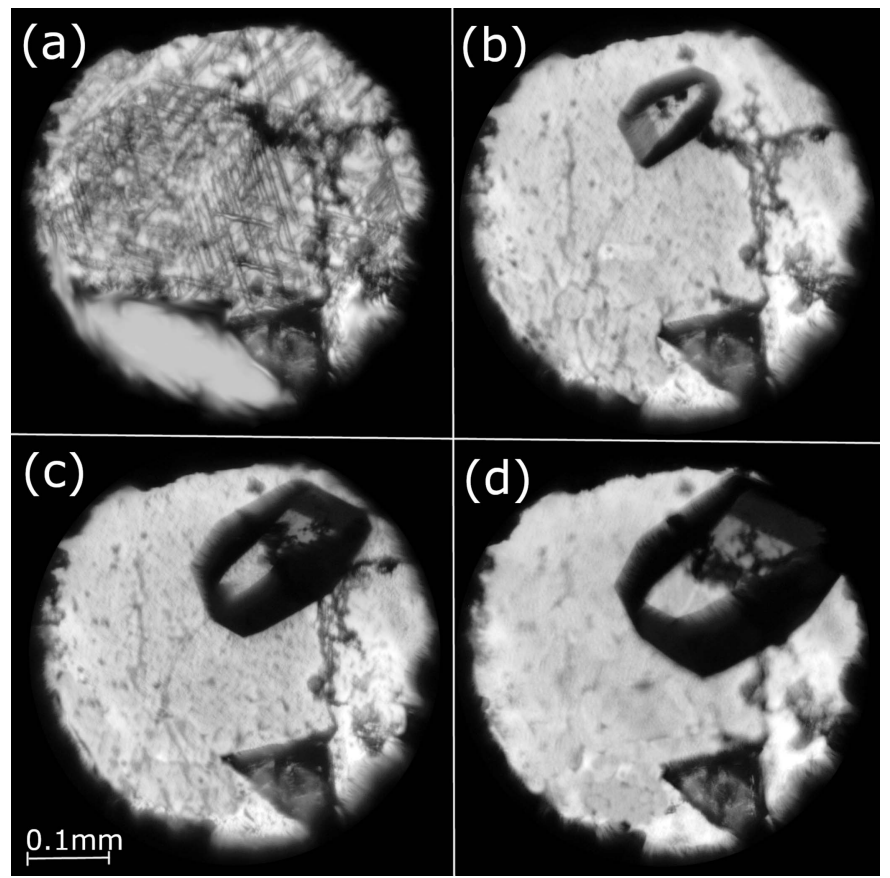

Figure 4

Stages of $3 \mathrm{SeC}\left(\mathrm{NH}_{2}\right)_{2} \cdot 2 \mathrm{H}_{2} \mathrm{O}$ single-crystal isochoric growth from the aqueous solution: $(a)$ spontaneous powder precipitation at $0.80 \mathrm{GPa}$, then dissolved at $339 \mathrm{~K}$; one seed at (b) $323 \mathrm{~K}$; $(c) 316 \mathrm{~K}$ and $(d) 0.80 \mathrm{GPa} /$ $296 \mathrm{~K}$. The ruby chip for pressure calibration is located close to the bottom edge of the gasket.
Table 1

Selected crystal data of $\mathrm{SeC}\left(\mathrm{NH}_{2}\right)_{2}$ phase $\alpha$, phase $\beta$ and the duotritohydrate, all determined at $296 \mathrm{~K}$ ( $c f$. Tables S1-S3).

\begin{tabular}{llll}
\hline & $\alpha-\mathrm{SeC}\left(\mathrm{NH}_{2}\right)_{2}$ & $\beta-\mathrm{SeC}\left(\mathrm{NH}_{2}\right)_{2}$ & $3 \mathrm{SeC}\left(\mathrm{NH}_{2}\right)_{2} \cdot 2 \mathrm{H}_{2} \mathrm{O}$ \\
\hline Pressure (GPa) & 0.0001 & 0.21 & 0.52 \\
Crystal system & Trigonal & Monoclinic & Monoclinic \\
Space group & $P 3_{2}$ & $P 2_{1} / c$ & $C 2 / c$ \\
$a(\AA)$ & $15.2768(3)$ & $7.6155(13)$ & $8.2698(12)$ \\
$b(\AA)$ & $15.2768(3)$ & $8.4109(7)$ & $8.8726(8)$ \\
$c(\AA)$ & $13.0239(3)$ & $11.709(3)$ & $16.913(3)$ \\
$\beta\left({ }^{\circ}\right)$ & 90 & $100.46(3)$ & $90.205(17)$ \\
$V\left(\AA^{3}\right)$ & $2632.31(12)$ & $736.9(2)$ & $1241.0(3)$ \\
$Z, Z^{\prime}$ & 27,9 & 8,2 & $4,0.5$ \\
$D_{x}\left(\mathrm{~g} \mathrm{~cm}^{-3}\right)$ & 2.095 & 2.218 & 2.218 \\
\hline
\end{tabular}

(Fig. 2b) was due to strong scattering of the transmitting light on fine grains of the cracked sample. The initially single crystal, after exposure to pressure above $0.21 \mathrm{GPa}$, disintegrated into fine powder, falling apart when the sample was even gently touched after opening the DAC.

High-pressure recrystallization of aqueous solution yielded the same $\alpha-\mathrm{SeC}\left(\mathrm{NH}_{2}\right)_{2}$ up to $0.21 \mathrm{GPa}$, both at isothermal and isochoric conditions (Fig. 3). The single crystals of $\alpha$-SeC( $\left(\mathrm{NH}_{2}\right)_{2}$ grown of aqueous solution could be compressed to $0.30 \mathrm{GPa}$, and then it crushed (i.e. pulverized due to a strongly discontinuous reconstructive phase transformation), similarly when the samples obtained at normal conditions were compressed to above $0.21 \mathrm{GPa}$. This value of $0.30 \mathrm{GPa}$ was confirmed for several crystals either compressed in water or grown of aqueous solution. Above $0.50 \mathrm{GPa}$ selenourea
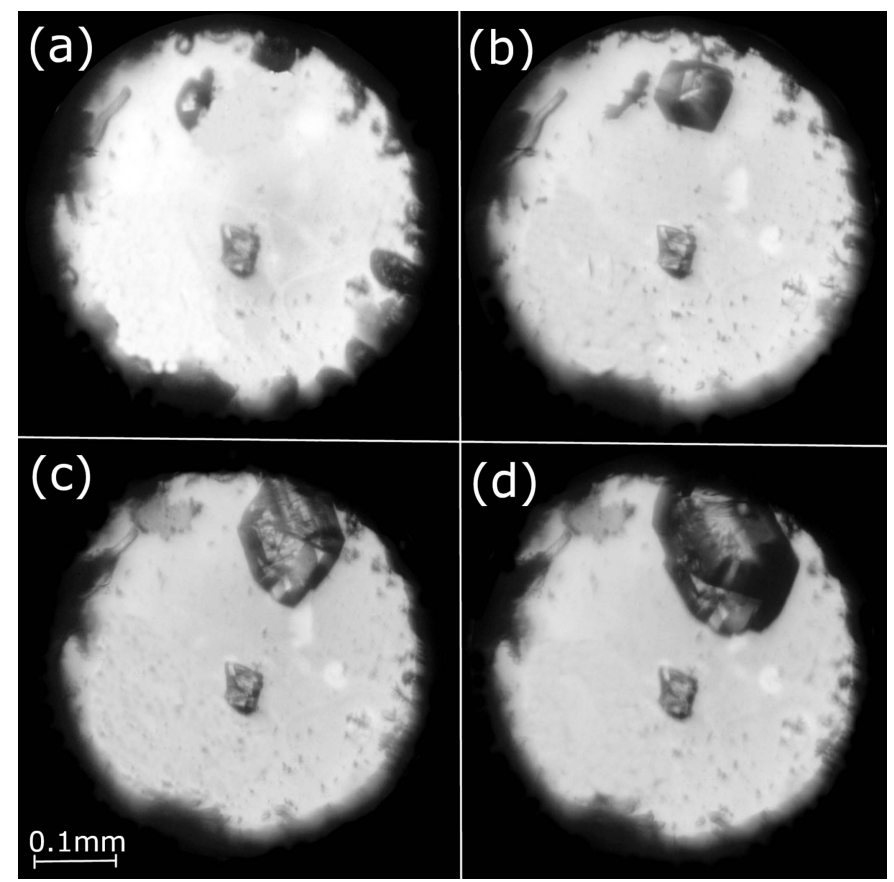

Figure 5

Single crystal of $\operatorname{SeC}\left(\mathrm{NH}_{2}\right)_{2}$ polymorph $\beta$ grown from the methanol solution under isochoric conditions in the DAC chamber at (a) $383 \mathrm{~K} ;(b)$ $363 \mathrm{~K} ;(c) 333 \mathrm{~K}$ and $(d) 1.01 \mathrm{GPa} / 296 \mathrm{~K}$. Several ruby chips for pressure calibration are scattered around the DAC chamber. 
duotritohydrate $3 \mathrm{SeC}\left(\mathrm{NH}_{2}\right)_{2} \cdot 2 \mathrm{H}_{2} \mathrm{O}$ was obtained (Fig. 4 and Figs. S4-S5). In order to prevent this hydrate formation, for the next crystallizations the methanol solution was used (Fig. 5). These recrystallizations yielded a new phase $\beta$.

Single-crystal high-pressure data were recorded on KUMA KM4-CCD and Xcalibur diffractometers equipped with EOS$\mathrm{CCD}$ detectors, according to the procedure described previously (Budzianowski \& Katrusiak, 2004). The CrysAlisPro software (2015) was used for collecting diffraction data and their preliminary reduction. Reflections that overlapped with diamond reflections were eliminated, and corrections for the DAC and sample absorption and for beam shadowing by the gasket were applied. OLEX2 (Dolomanov et al., 2009) was used, the crystal structures were solved by direct methods with program SHELXT (Sheldrick, 2015a) and refined by leastsquares with SHELXL (Sheldrick, 2015b). Anisotropic displacement factors were generally applied for non-hydrogen atoms. The $\mathrm{H}$ atoms in $\mathrm{SeC}\left(\mathrm{NH}_{2}\right)_{2}$ were located from the molecular geometry $(\mathrm{N}-\mathrm{H}$ distance $0.86 \AA)$ and their $U_{\text {iso }}$ value was constrained as $U_{\text {eq }}$ of $\mathrm{N}$ carriers. The water $\mathrm{H}$ atoms were located from difference Fourier maps and then the positions of $\mathrm{H}_{2} \mathrm{O}$ molecules were refined as rigid units; the $U_{\text {iso }}$ values of the $\mathrm{H}$ atoms were constrained to $1.2 \times$ the $U_{\text {eq }}$ value of the oxygen atoms. Structural drawings were prepared using program Mercury CSD 4.0 (Macrae et al., 2020). Selected crystal data are given in Table 1. Experimental details and crystal data are given in Tables S1-S3.

Because on increasing pressure above about $0.2-0.3 \mathrm{GPa}$ the singe crystals of $\alpha-\mathrm{SeC}\left(\mathrm{NH}_{2}\right)_{2}$ disintegrated into powder, and on releasing pressure the in situ grown single crystal

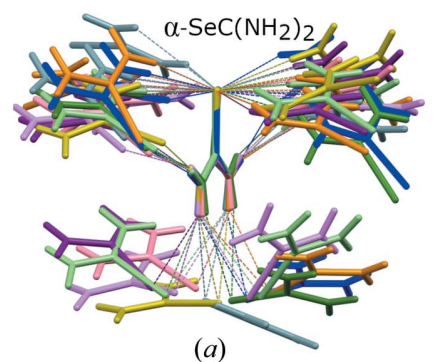

(a)

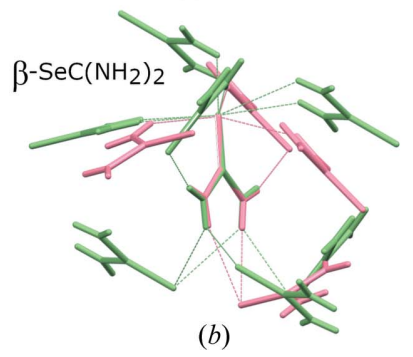

(b)

Figure 6

Exactly superimposed independent $\mathrm{SeC}\left(\mathrm{NH}_{2}\right)_{2}$ molecules and their $\mathrm{NH} \cdots$ Se bonded neighbours in phases $(a) \alpha$ at $0.1 \mathrm{MPa}$ and $(b) \beta$ at $0.21 \mathrm{GPa}$. The Se $\cdots \mathrm{H}$ bonds are marked by dotted lines. The colours mark patterns hydrogen bonded to central molecules labelled: 1 (pink), 2 (light green), 3 (deep green), 4 (grey), 5 (blue), 6 (purple), 7 (violet), 8 (orange) and 9 (dark yellow). (c) Exactly superimposed urea $\mathrm{OC}\left(\mathrm{NH}_{2}\right)_{2}$ molecules and their NH...O bonded neighbours in phases I (pink), III (light green) and IV (deep green, c.f. Fig. S6-S8).
$\beta$-SeC( $\left(\mathrm{NH}_{2}\right)_{2}$ pulverized too, we have used powder diffraction for confirming the phases of the powder samples. For the increased-pressure runs, the powder sample was recovered from the DAC and then placed on the single-crystal silicon plate and the powder diffraction pattern was recorded using a Bruker AXS D8 Advance powder diffractometer equipped with a Johansson monochromator, $\lambda\left(\mathrm{Cu} K \alpha_{1}\right)=1.54056 \AA$. For the reducing-pressure runs to below the transition of the in situ grown $\beta$ - $\mathrm{SeC}\left(\mathrm{NH}_{2}\right)_{2}$ sample, its pressure pattern was recorded immediately below the transition in the DAC using the KUMA KM4-CCD and Xcalibur diffractometers, $\lambda(\operatorname{Mo} K \alpha)=0.71073 \AA$.
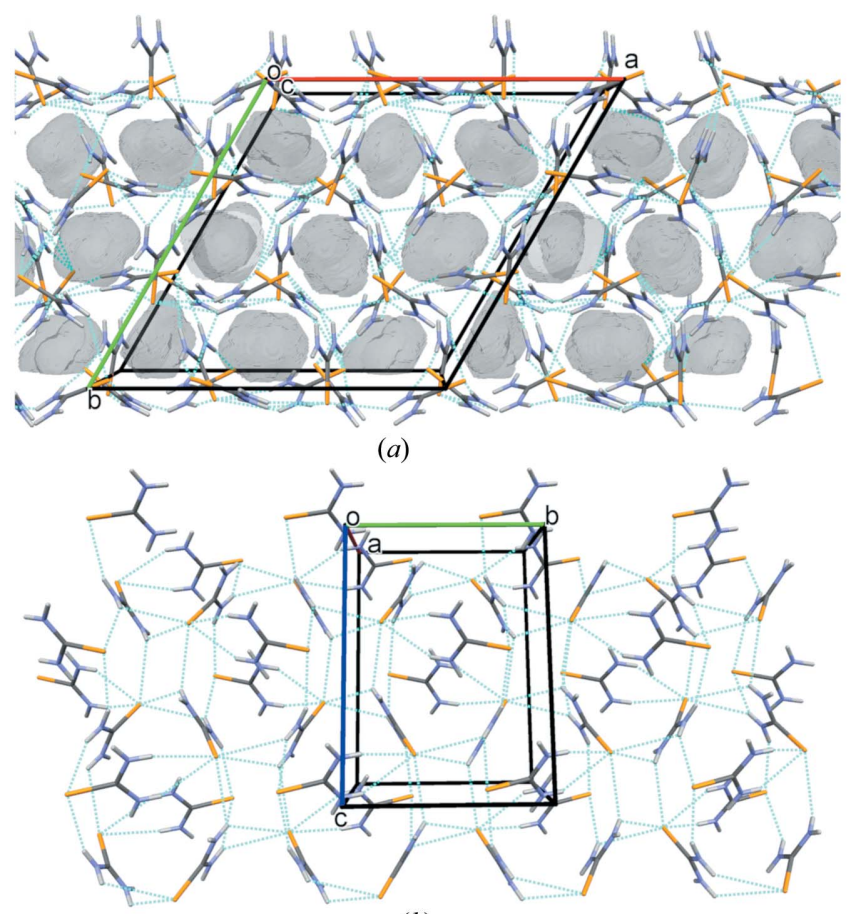

(b)

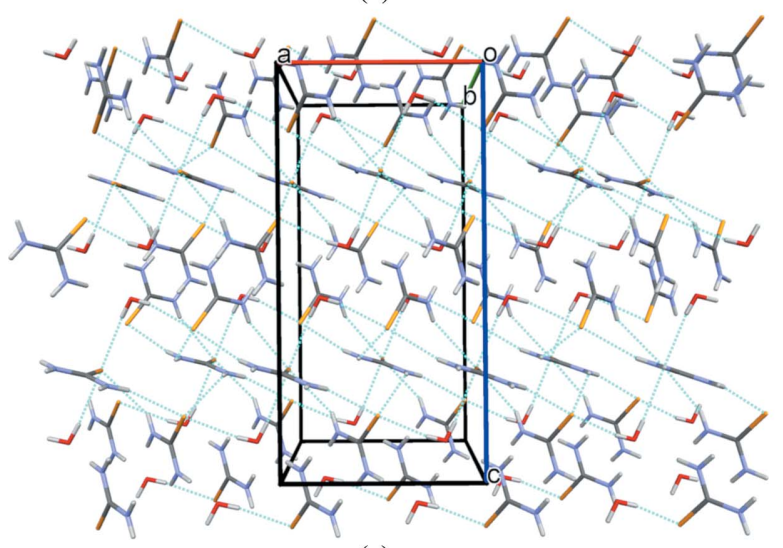

(c)

Figure 7

Autostereographic projections (Katrusiak, 2001) of $\mathrm{SeC}\left(\mathrm{NH}_{2}\right)_{2}$ phases: (a) $\alpha \quad$ at $0.1 \mathrm{MPa}$ (c.f. Fig. S9); (b) $\beta$ at $0.21 \mathrm{GPa}$; and (c) $3 \mathrm{SeC}\left(\mathrm{NH}_{2}\right)_{2} \cdot 2 \mathrm{H}_{2} \mathrm{O}$ at $0.52 \mathrm{GPa}$. Hydrogen bonds $\mathrm{NH} \cdots \mathrm{Se}$ and $\mathrm{OH}$...Se are indicated by blue dotted lines; the voids shown in grey in phase $\alpha$ were calculated by Mercury (Macrae et al., 2008) for the probe radius of $1.0 \AA$ and grid step $0.1 \AA$ (c.f. Fig. S10). 


\section{Discussion}

The high-pressure study of $\alpha$-SeC( $\left(\mathrm{NH}_{2}\right)_{2}$ addresses the intriguing aspects of its structure, such as the high $Z^{\prime}$ value (Fig. 6), the enantiomeric symmetry and large voids with a diameter of $2.7 \AA$, absent in urea and thiourea. The large voids in $\alpha$-SeC( $\left(\mathrm{NH}_{2}\right)_{2}$ (Figs. 7, S9 and S10) can be connected with its collapse under pressure and the transformation to more dense phase $\beta$.

The transition from phase $\alpha$ compressed in glycerine to phase $\beta$ takes place at $0.21 \mathrm{GPa}$. This transition point can be clearly observed visually, as the crystal pulverized (Fig. 3). The $\alpha$-to- $\beta$ transition is reversible. We confirmed by X-ray powder diffraction in situ in the DAC that phase $\alpha$ compressed above $0.21 \mathrm{GPa}$ transforms to phase $\beta$ and that on releasing pressure it transforms back to phase $\alpha$. The powder diffraction patterns are compared in Figs. S12 and S13. The crystal structure of phase $\beta$ has been solved by X-ray diffraction for the in situ grown single-crystal (Tables 1 and S1-S3). The transition is strongly reconstructive and involves a considerable volume drop of over $3 \AA^{3}$ per one molecule (Figs. 8 and S11). The transition reduces the $Z^{\prime}$ number from 9 to 2 (Table 1). The intermolecular distances involving Se atoms show that the differences in the molecular environment become considerably reduced in phase $\beta$ compared to phase $\alpha$ (Fig. S14).

The reversibility of the $\alpha-\beta$ phase transition can be associated with the strain induced in the $\beta$-SeC $\left(\mathrm{NH}_{2}\right)_{2}$ hydrogen bonds $\mathrm{NH} \cdots$ Se. The directional character of these hydrogen

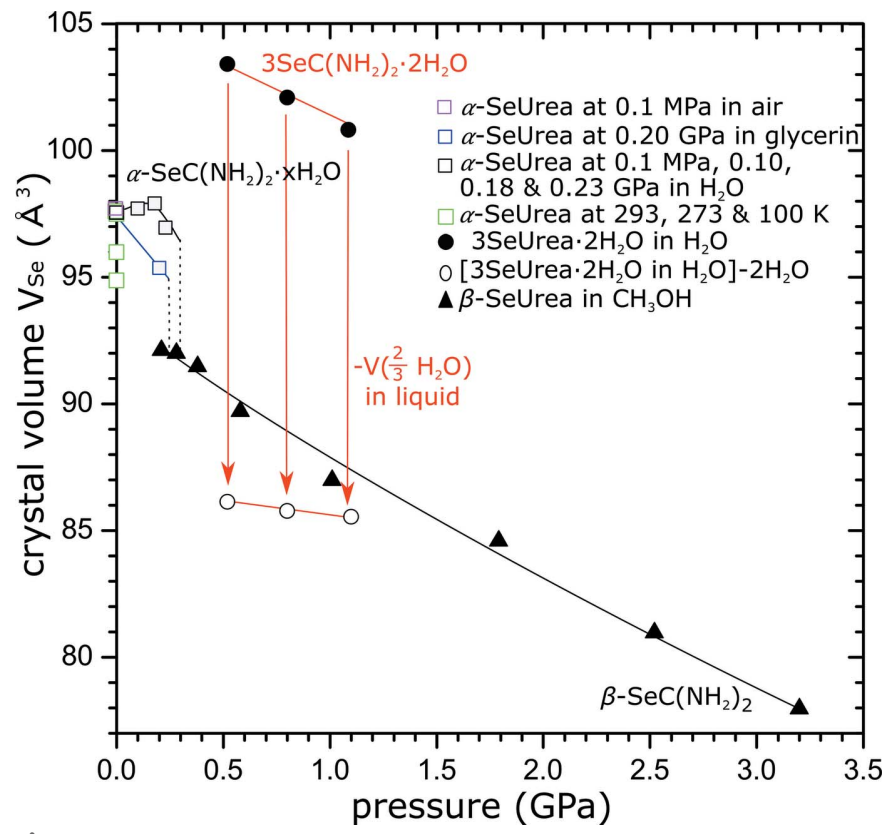

Figure 8

Crystal volume $V_{\mathrm{Se}}$ (equal to the unit-cell $V$ divided by the number of selenourea molecules, $\left.N_{\mathrm{Se}}\right)$ for $\mathrm{SeC}\left(\mathrm{NH}_{2}\right)_{2}$ phases $\alpha, \alpha$-SeC $\left(\mathrm{NH}_{2}\right)_{2} \cdot x \mathrm{H}_{2} \mathrm{O}$, phase $\beta$ and the duotritohydrate $3 \mathrm{SeC}\left(\mathrm{NH}_{2}\right)_{2} \cdot 2 \mathrm{H}_{2} \mathrm{O}$ compressed (at $296 \mathrm{~K}$ ) in $\mathrm{H}_{2} \mathrm{O}$ and methanol (marked in black), and in glycerine (blue). Red arrows down indicate the difference between $V_{\mathrm{Se}}$ of duotritohydrate and the $\frac{2}{3}$ part of the molecular volume of $\mathrm{H}_{2} \mathrm{O}$ in compressed water (Bridgman, 1935) and ice VI (Kuhs et al., 1984). The $100 \mathrm{~K}, 173 \mathrm{~K}$ and 293 K/0.1 MPa points (green) were determined by Luo \& Dauter (2017) and Rutherford \& Calvo (1969). bonds is apparent from the $\mathrm{N}-\mathrm{H} \cdots$ Se angles in phase $\alpha$, all assuming values between 143 and $171^{\circ}$ (Fig. 9). At $0.20 \mathrm{GPa}$, all but one of these angles become larger than $149^{\circ}$. The transition to phase $\beta$ breaks two of eight independent $\mathrm{NH} \cdot$. Se bonds to about $130^{\circ}$ or less (Fig. 9). The strain in these bent bonds can be responsible for the reverse transition to phase $\alpha$. Also other reasons can be responsible for destabilizing phase $\mathrm{SeC}\left(\mathrm{NH}_{2}\right)_{2}$ below $0.21 \mathrm{GPa}$, for example, the strain due to stretched H-bonds in NH...Se (their optimum directions and short lengths are sacrificed for the closer packing of molecules in phase $\beta$ ) as well as the strain of nonbonding Se...Se contacts compressed to distances shorter than the doubled van der Waals radius of Se (Fig. S14). On the other hand, the $\mathrm{SeC}\left(\mathrm{NH}_{2}\right)_{2}$ phases, and similarly its analogs $\mathrm{OC}\left(\mathrm{NH}_{2}\right)_{2}$ and $\mathrm{SC}\left(\mathrm{NH}_{2}\right)_{2}$, display a wide variety of packing

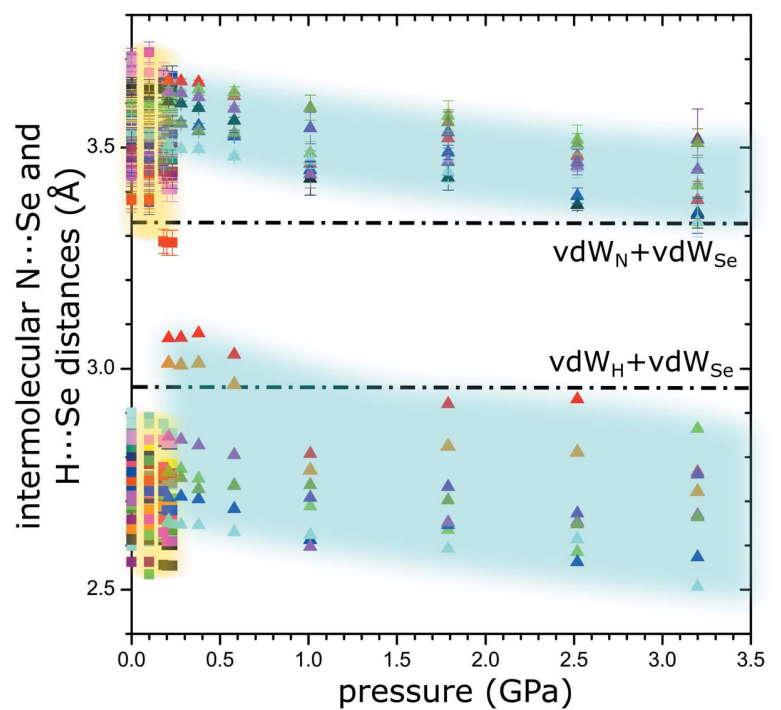

(a)

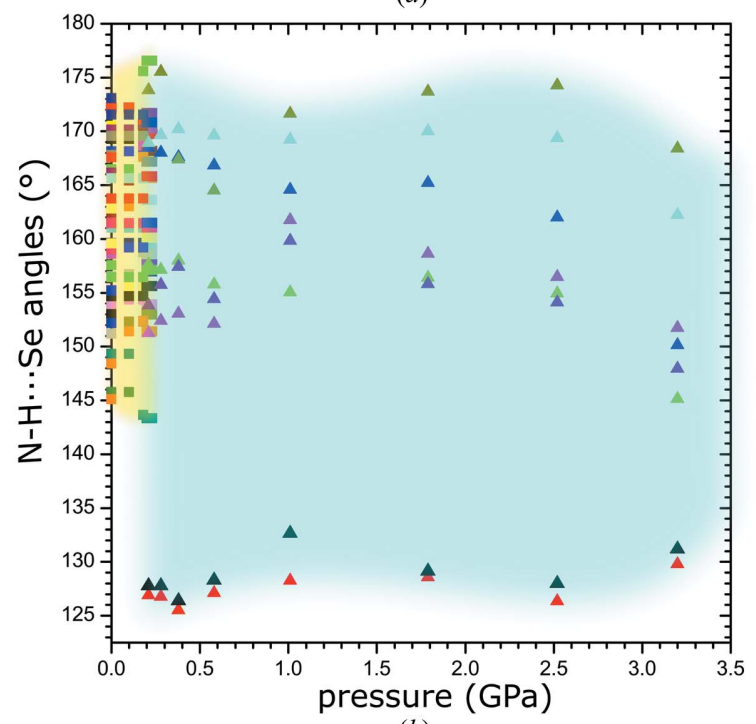

(b)

Figure 9

Dimensions of $\mathrm{NH} \cdots \mathrm{Se}$ hydrogen bonds in $\mathrm{SeC}\left(\mathrm{NH}_{2}\right)_{2}$ phases: (a) distances $\mathrm{N} \cdots \mathrm{Se}$ and $\mathrm{H} \cdots \mathrm{Se}$; and $(b)$ angles $\mathrm{NH} \cdots \mathrm{Se}$ measured as a function of pressure in $\alpha-\mathrm{SeC}\left(\mathrm{NH}_{2}\right)_{2}$ and $\beta$-SeC( $\left(\mathrm{NH}_{2}\right)_{2}$ (c.f. Fig. S15). The distances and angles in phase $\alpha$ are highlighted yellow, and those in phase $\beta$ are highlighted light turquoise. 

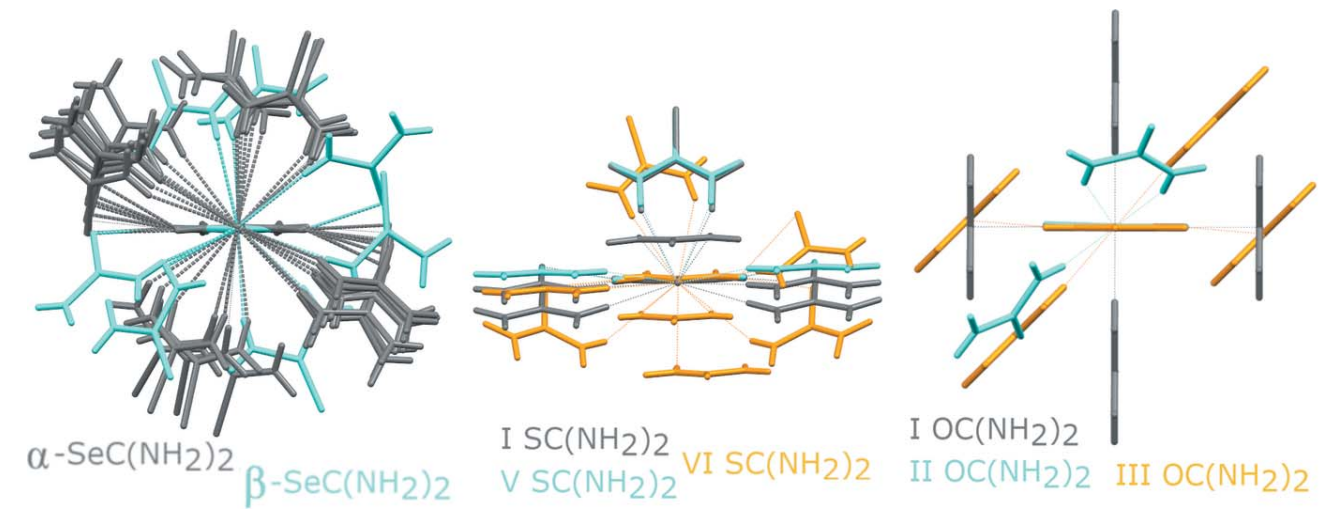

Figure 10

Exactly superimposed independent $X \mathrm{C}\left(\mathrm{NH}_{2}\right)_{2}$ molecules $(X=\mathrm{Se}, \mathrm{O}, \mathrm{S})$ and their $\mathrm{NH} \cdots X$ bonded neighbours in selenourea (phases $\alpha$ and $\beta$ ); urea (phases I, III and IV) and thiourea (phases I, V and VI), all viewed from the side of atom $X$ along the $X=\mathrm{C}$ bond, with the mean plane of the central molecule horizontal ( $c f$. Fig. 6 and Fig. S16).

motifs, despite the directional hydrogen bonds dominating their cohesion forces (Fig. 10). Fig. 9 shows that the directionality (measured by $\mathrm{NH}$. . Se angles) and even the $\mathrm{H}$. . Se bond length are considerably more scattered in $\beta$-SeC( $\left(\mathrm{NH}_{2}\right)_{2}$ than in phase $\alpha$, mainly due to the two bent hydrogen bonds. However, the N...Se distances of $\mathrm{NH}$...Se bonds are much better defined in phase $\beta$, which is a consequence of the prevailing role of molecular close packing under high pressure.

We found that the compression of phase $\alpha$ in water leads to a higher volume compared to the compression in glycerine (Fig. 9). This result suggests that some water molecules can penetrate into the voids and therefore the crystal initially increases its volume. Apparently, some of the voids are inaccessible for the water molecules and therefore such partly hydrated $\alpha$-SeC( $\left(\mathrm{NH}_{2}\right)_{2} \cdot x \mathrm{H}_{2} \mathrm{O}$ crystals transform to phase $\beta$ at $0.30 \mathrm{GPa}$, i.e. nearly $0.10 \mathrm{GPa}$ higher than when glycerine was used as the hydrostatic fluid.

The penetration of $\mathrm{H}_{2} \mathrm{O}$ into the voids of $\alpha-\mathrm{SeC}\left(\mathrm{NH}_{2}\right)_{2}$ can be considered as a precursor of the formation of the hydrate. Indeed, the recrystallization at $0.50 \mathrm{GPa}$ from aqueous solution yields the duotritohydrate $3 \mathrm{SeC}\left(\mathrm{NH}_{2}\right)_{2} \cdot 2 \mathrm{H}_{2} \mathrm{O}$. This crystal (Fig. 5) is isostructural with the analogous thiourea duotritohydrate, 3SC( $\left(\mathrm{NH}_{2}\right)_{2} \cdot 2 \mathrm{H}_{2} \mathrm{O}$ (Tomkowiak \& Katrusiak, 2018). Both $3 \mathrm{SeC}\left(\mathrm{NH}_{2}\right)_{2} \cdot 2 \mathrm{H}_{2} \mathrm{O}$ and $3 \mathrm{SC}\left(\mathrm{NH}_{2}\right)_{2} \cdot 2 \mathrm{H}_{2} \mathrm{O}$ decompose on releasing pressure and our attempts to recover these crystals to ambient conditions failed. Another analogy between $3 \mathrm{SeC}\left(\mathrm{NH}_{2}\right)_{2} \cdot \mathrm{H}_{2} \mathrm{O}$ and $3 \mathrm{SC}\left(\mathrm{NH}_{2}\right)_{2} \cdot \mathrm{H}_{2} \mathrm{O}$ is that they were in situ grown in the DAC from aqueous solutions, which hampers the experiments above $1.00 \mathrm{GPa}$ due to the crystallization of water into ice VI. Therefore at present we are not certain if the duotritohydrates are stable at still higher pressure.

The unit-cell volume divided by the number of selenourea molecules $\left(V_{\mathrm{Se}}=V / N_{\mathrm{Se}}\right)$ for $3 \mathrm{SeC}\left(\mathrm{NH}_{2}\right)_{2} \cdot 2 \mathrm{H}_{2} \mathrm{O}$, after the subtraction of the volume of water molecules contained in this volume, according to formula $V_{\mathrm{Se}}-\frac{2}{3} V_{\mathrm{H}_{2} \mathrm{O}}$ (see Fig. 8), is significantly smaller compared to the molecular volume with increasing pressure and it can be estimated to be similar to the molecular volume $V_{\mathrm{m}}$ of $\beta$-SeC( $\left(\mathrm{NH}_{2}\right)_{2}$ at $0.5 \mathrm{GPa}$, but with increasing pressure their difference is reduced and it can be estimated to be similar to the molecular volume $V_{\mathrm{m}}$ of $\beta$-SeC $\left(\mathrm{NH}_{2}\right)_{2}$ at about $1.50 \mathrm{GPa}$. A similar decrease of the volume difference was observed for the analogous duotritohydrate thiourea, $3 \mathrm{SC}\left(\mathrm{NH}_{2}\right)_{2} \cdot 2 \mathrm{H}_{2} \mathrm{O}$ : the substitution $V_{\mathrm{S}}-\frac{2}{3} V_{\mathrm{H}_{2} \mathrm{O}}$ result becomes similar to $V_{\mathrm{m}}$ of thiourea phase VI, where $V_{\mathrm{S}}$ is the crystal volume per one sulfur atom), and no hydrates of thiourea could be obtained above $1.00 \mathrm{GPa}$ (Tomkowiak et al., 2013; Tomkowiak \& Katrusiak, 2018). So it is possible that the unsolvated phases of $\mathrm{SeC}\left(\mathrm{NH}_{2}\right)_{2}$ and $\mathrm{SC}\left(\mathrm{NH}_{2}\right)_{2}$ become more stable than the hydrates about $1.00 \mathrm{GPa}$.

\section{Conclusions}

We have established that high pressure destabilizes the structure of $\alpha$-SeC $\left(\mathrm{NH}_{2}\right)_{2}$ and reduces its exceptionally high $Z^{\prime}$ number from 9 to 2 . It appears that the large $Z^{\prime}$ number in $\alpha$-SeC $\left(\mathrm{NH}_{2}\right)_{2}$ is a consequence of no strong preference for the molecules to aggregate in one specific manner. This feature of the crystal structure can be described as a labile crystal environment of molecules. Apparently this labile environment is more pronounced in $\mathrm{SeC}\left(\mathrm{NH}_{2}\right)_{2}$ than in its $\mathrm{S}$ and $\mathrm{O}$ analogues. Owing to the presence of voids, somewhat smaller than the size of water molecules, $\alpha-\mathrm{SeC}\left(\mathrm{NH}_{2}\right)_{2}$ is differently compressed in water and in liquids consisting of larger molecules. Phase $\alpha$ collapses below $0.21 \mathrm{GPa}$ in glycerine, but in water it can withstand $0.30 \mathrm{GPa}$. In the structure of phase $\beta$ the close packing of molecules is achieved at the cost of two NH...Se hydrogen bonds significantly bent. Although the crystal structures of selenourea polymorphs are considerably different than those of thiourea, their $3 \mathrm{SeC}\left(\mathrm{NH}_{2}\right)_{2} \cdot 2 \mathrm{H}_{2} \mathrm{O}$ and $3 \mathrm{SC}\left(\mathrm{NH}_{2}\right)_{2} \cdot 2 \mathrm{H}_{2} \mathrm{O}$ duotritohydrates are closely isostructural. No $\mathrm{SeC}\left(\mathrm{NH}_{2}\right)_{2}$ analogue of thiourea monohydrate $\mathrm{SC}\left(\mathrm{NH}_{2}\right)_{2} \cdot \mathrm{H}_{2} \mathrm{O}$ could be obtained in our high-pressure study. 


\section{Funding information}

This research was supported by funding from the Polish National Science Centre (OPUS 10 No. UMO-2015/19/B/ST5/ 00262).

\section{References}

Andrzejewski, M. \& Katrusiak, A. (2017). J. Phys. Chem. Lett. 8, 929 935.

Anioła, M. \& Katrusiak, A. (2017). Cryst. Growth Des. 17, 31343141.

Bridgman, P. W. (1935). J. Chem. Phys. 3, 597-605.

Budzianowski, A. \& Katrusiak, A. (2004). In High-Pressure Crystallography edited by A. Katrusiak and P. McMillan. NATO Science Series (Series II: Mathematics, Physics and Chemistry), Vol. 140, pp. 101-112. Dordrecht: Springer.

Dolomanov, O. V., Bourhis, L. J., Gildea, R. J., Howard, J. A. K. \& Puschmann, H. (2009). J. Appl. Cryst. 42, 339-341.

Dziubek, K., Podsiadło, M. \& Katrusiak, A. (2007). J. Am. Chem. Soc. 129, 12620-12621.

Girard, P., Aliev, A. E., Guillaume, F., Harris, K. D. M., Hollingsworth, M. D., Dianoux, A.-J. \& Jonsen, P. (1997). Phys. B, 234-236, 112-114.

Girard, P., Aliev, A. E., Guillaume, F., Harris, K. D. M., Hollingsworth, M. D., Dianoux, A.-J. \& Jonsen, P. (1998). J. Chem. Phys. 109, 4078-4089.

Groom, C. R., Bruno, I. J., Lightfoot, M. P. \& Ward, S. C. (2016). Acta Cryst. B72, 171-179.

Hazen, R. M. \& Finger, L. W. (1982). Comparative Crystal Chemistry: Temperature, Pressure, Composition and the Variation of Crystal Structure. Chichester and New York: John Wiley and Sons.

Hollingsworth, M. D., Brown, M. E., Dudley, M., Chung, H., Peterson, M. L. \& Hillier, A. C. (2002a). Angew. Chem. Int. Ed. 41, 965-969.

Hollingsworth, M. D., Peterson, M. L., Pate, K. L., Dinkelmeyer, B. \& Brown, M. E. (2002b). J. Am. Chem. Soc. 124, 2094-2095.

Hollingsworth, M. D., Peterson, M. L., Rush, J. R., Brown, M. E., Abel, M. J., Black, A. A., Dudley, M., Raghothamachar, B., WernerZwanziger, U., Still, E. J. \& Vanecko, J. A. (2005). Cryst. Growth Des. 5, 2100-2116.

Hollingsworth, M. D., Werner-Zwanziger, U., Brown, M. E., Chaney, J. D., Huffman, J. C., Harris, K. M. D. \& Smart, S. P. (1999). J. Am. Chem. Soc. 121, 9732-9733.
Katrusiak, A. (2001). J. Mol. Graphics Modell. 19, 363-367.

Katrusiak, A. (2008). Acta Cryst. A64, 135-148.

Kuhs, W. F., Finney, J. L., Vettier, C. \& Bliss, D. V. (1984). J. Chem. Phys. 81, 3612-3623.

Luo, Z. \& Dauter, Z. (2017). PLoS One, 12, e0171740.

Macrae, C. F., Sovago, I., Cottrell, S. J., Galek, P. T. A., McCabe, P., Pidcock, E., Platings, M., Shields, G. P., Stevens, J. S., Towler, M. \& Wood, P. A. (2020). J. Appl. Cryst. 53, 226-235.

Mao, H. K., Xu, J. \& Bell, P. M. (1986). J. Geophys. Res. 91, 46734676.

Marciniak, J., Bąkowicz, J., Dobrowolski, M. A., Dziubek, K. F., Kaźmierczak, M., Paliwoda, D., Rajewski, K. W., Sobczak, S., Stachowicz, M. \& Katrusiak, A. (2016). Cryst. Growth Des. 16, 1435-1441.

Merrill, L. \& Bassett, W. A. (1974). Rev. Sci. Instrum. 45, 290-294.

Olejniczak, A. \& Katrusiak, A. (2008). J. Phys. Chem. B, 112, 71837190.

Olejniczak, A., Ostrowska, K. \& Katrusiak, A. (2009). J. Phys. Chem. $C, \mathbf{1 1 3}, 15761-15767$.

Patyk, E., Podsiadło, M. \& Katrusiak, A. (2015). Cryst. Growth Des. 15, 5670-5674.

Patyk-Kaźmierczak, E., Warren, M. R., Allan, D. R. \& Katrusiak, A. (2017). Phys. Chem. Chem. Phys. 19, 9086-9091.

Piermarini, G. J., Block, S., Barnett, J. D. \& Forman, R. A. (1975). J. Appl. Phys. 46, 2774-2780.

Rigaku Oxford Diffraction (2015). CrysAlisPro. Rigaku Oxford Diffraction, Yarnton, England.

Roszak, K. \& Katrusiak, A. (2017). J. Phys. Chem. C, 121, 778-784.

Rutherford, J. S. \& Calvo, C. (1969). Z. Kristallogr. 128, 229-258.

Seryotkin, Y. V., Drebushchak, T. N. \& Boldyreva, E. V. (2013). Acta Cryst. B69, 77-85.

Sheldrick, G. M. (2015a). Acta Cryst. A71, 3-8.

Sheldrick, G. M. (2015b). Acta Cryst. C71, 3-8.

Taouss, C., Thomas, L. \& Jones, P. G. (2013). CrystEngComm, 15, 6829-6836.

Tomkowiak, H. \& Katrusiak, A. (2018). J. Phys. Chem. C, 122, 5064 5070 .

Tomkowiak, H., Olejniczak, A. \& Katrusiak, A. (2013). Cryst. Growth Des. 13, 121-125.

Toudic, B., Garcia, P., Odin, C., Rabiller, P., Ecolivet, C., Collet, E., Bourges, P., McIntyre, G. J., Hollingsworth, M. D. \& Breczewski, T. (2008). Science, 319, 69-71. 